\title{
A CASE OF TRANSFUSION SYPHILIS
}

\author{
BY \\ G. O. MAYNE \\ Graded Venereologist, R.A.M.C.
}

The accidental transmission of syphilis as the result of blood transfusion is properly regarded as a medical catastrophe. It is, however, conceivable that under certain conditions the risk might be considered justifiable if the immediate aim was the preservation of life. The case shortly to be described may be regarded as falling within this category.

Rein and others (1938) estimated 68 cases in the literature, but Stokes (1944) asserts that " the reported incidence of transfusion syphilis is in ludicrous contrast to a reasonable estimate of its frequency," and suggests that reluctance to publish cases may for ever cloak its actual incidence.

\section{Case History}

A European male, aged 34, intelligent, co-operative, and of good physique, while resident in the tropics was involved in a fracas during which he was struck heavily on the nose. One week later he developed a profuse epistaxis, and his nose was packed in hospital. Despite this the hæmorrhage continued to a stage of extreme exsanguination. Two European volunteers were called for, and blood from each was transfused into the patient after cross-matching. Preliminary Kahn tests were not done on the donors. The patient's condition improved rapidly and he was able to leave hospital.

Six weeks later he began to experience violent headaches and pain in the left hypochondrium. About 10 days after the first onset of symptoms he was readmitted to hospital complaining of fever, headache, pain in the left hypochondrium, generalized pains in the bones, and slight sore throat. Immediately on admission blood films showed the presence of malignant tertian malarial parasites, and a course of mepacrine was therefore started, with the result that some symptomatic relief was obtained although the patient remained febrile. Radiographs of chest and sinuses were normal. Examination of the cerebrospinal fluid showed 7 cells per c.mm. ; protein, $20 \mathrm{mg}$. per $100 \mathrm{c.cm}$. ; Kahn test negative. White blood cells were 6,000 per c.mm., and the differential count was normal. The Widal and Weil-Felix tests were negative.

Six days after admission a faint maculo-papular rash appeared, mainly situated on the trunk, and a blood Kahn test was reported "positive." Three days later a second Kahn test was reported as +++ , the fever persisted, and the rash grew more marked. There were no penile or other suspicious sores, and no mucous lesions. Five days later a provocative injection of neoarsphenamine $(0.1 \mathrm{~g}$.) was given, and on the following day the rash was. seen to be still more pronounced, while the Kahn was reported as ++++ . A standard course of therapy with neoarsphenamine and bismuth was then started. In 6 days the rash had disappeared and the patient was symptom-free and fit to leave hospital.

\section{Discussion}

Unfortunately technical and geographical difficulties prevented the performance of the Wassermann reaction in addition to and as a check on the Kahn tests, and in consequence caution had to be observed in interpreting the serological findings in view of the possibility of false positives due to the proven coincident malarial infection. However, it was ultimately considered that the diagnosis of early syphilis was established beyond reasonable doubt on the basis of the typical rash, the repeatedly strongly positive blood test, and the immediate clinical response to specific treatment.

Before blood transfusion was accepted as the undoubted mode of infection, however, the personal and family history were closely investigated, and here it may be stated that the patient appeared on several different occasions and to several independent medical observers to be a reliable witness. He had no previous history of venereal disease, nor any previous penile, genital, or labial sores. He was married, and had 4 children; his wife and the children were healthy. He stated that his last sexual contact was with his wife, 
and that it had occurred 16 months previously, before his departure overseas.

After the diagnosis had been established, attempts were made to trace and examine the donors. One was found to be clinically and serologically negative, but the other had left the area. Subsequently this second donor was traced and was examined at another hospital, whence information was later forthcoming that he was found to be a sero-positive latent syphilitic $(\mathrm{Kahn}++)$.

\section{Summary and Conclusions}

1. A case of early syphilis with coincident malaria is described, in which the diagnosis was based on the presence of a typical maculopapular rash, a strongly positive blood Kahn (the test being repeated 4 times), aggravation of the rash, and intensification of the degree of positivity of the Kahn test after provocative neoarsphenamine, and finally clinical improvement and symptomatic relief following the institution of anti-syphilitic therapy.

2. Furthermore, it is believed that the disease was acquired as the result of blood transfusion, because the patient denied the possibility of exposure during the preceding 16 months, his personal and family history were entirely negative, there were no signs of previous genital or other suspicious scarring, the time interval between the transfusion and the onset of symptoms was suggestive ( 6 weeks), and one of the two blood donors was found on subsequent examination to have a blood Kahn of ++ .

3. Consideration of this case serves to emphasize the fact that, before any transfusion in which fresh blood is to be used, the following procedures should be carried out on every donor : (a) complete physical examination of oral mucosa, trunk, anus, and genitalia ; (b) Kahn test or slide agglutination test (where facilities exist); (c) thick blood film for malarial parasites (in malarious areas).

4. Should it ever become vital to employ the blood of an untested donor in an acute emergency, $10 \mathrm{mg}$. of neoarsphenamine should be added to each $100 \mathrm{c.cm}$. of citrated blood as a safeguard, as recommended by Kast and others (1939). Alternatively, mapharside (10 mg. per $500 \mathrm{c.cm}$.) may be used (Eichenlaub and others, 1941).

I wish to thank the Director-General, Army Medical Services, for permission to publish this report, and Lt.-Col. R. R. Willcox, R.A.M.C., for much helpful advice.

\section{REFERENCES}

Eichenlaub, F. J., Stolar, R., and Wode; A. (1941). Arch. Derm. Syph., Chicago, 44, 441.

Kast, C. C., Peterson, C. W., and Kolmer, J. A. (1939). Amer. J. Syph., 23, 150.

Rein, C. R., Wise, F., and Cukerbaum, A. R. (1938). J. Amer. med. Ass., 110, 13.

Stokes, J. H. (1944). " Modern Clinical Syphilology." 3rd Edit. W. B. Saunders, Philadelphia. 